\title{
Towards an Integrated Framework for Invigorating Process Models: A Research Agenda
}

Citation for published version (APA):

Aysolmaz, B., \& Reijers, H. A. (2016). Towards an Integrated Framework for Invigorating Process Models: A Research Agenda. In BPM 2015: Business Process Management Workshops (pp. 552-558). Springer. Lecture Notes in Business Information Processing Vol. 256 https://doi.org/10.1007/978-3-319-42887-1_44

Document status and date:

Published: 22/07/2016

DOI:

10.1007/978-3-319-42887-1_44

Document Version:

Accepted author manuscript (Peer reviewed / editorial board version)

\section{Please check the document version of this publication:}

- A submitted manuscript is the version of the article upon submission and before peer-review. There can be important differences between the submitted version and the official published version of record.

People interested in the research are advised to contact the author for the final version of the publication, or visit the DOI to the publisher's website.

- The final author version and the galley proof are versions of the publication after peer review.

- The final published version features the final layout of the paper including the volume, issue and page numbers.

Link to publication

\footnotetext{
General rights Owners
rights.

- You may freely distribute the URL identifying the publication in the public portal. please follow below link for the End User Agreement:

www.umlib.nl/taverne-license

Take down policy

If you believe that this document breaches copyright please contact us at:

repository@maastrichtuniversity.nl

providing details and we will investigate your claim.
}

Copyright and moral rights for the publications made accessible in the public portal are retained by the authors and/or other copyright owners and it is a condition of accessing publications that users recognise and abide by the legal requirements associated with these

- Users may download and print one copy of any publication from the public portal for the purpose of private study or research.

- You may not further distribute the material or use it for any profit-making activity or commercial gain

If the publication is distributed under the terms of Article $25 \mathrm{fa}$ of the Dutch Copyright Act, indicated by the "Taverne" license above, 


\title{
Towards an Integrated Framework for Invigorating Process Models: A Research Agenda
}

\author{
Banu Aysolmaz ${ }^{1}$, Hajo A. Reijers ${ }^{1}$ \\ ${ }^{1}$ VU University Amsterdam, De Boelelaan 1105, 1081HV, Amsterdam, The Netherlands \\ \{b.e.aysolmaz, h.a.reijers\}@vu.nl
}

\begin{abstract}
Process models abstract a dynamic phenomenon in the form of a static representation. This contrast makes them difficult to comprehend. Innovative usage of dynamic multimedia techniques in combination with static process model visualization knowledge remains an opportunity to address this problem. In this paper, we unfold our research plan to invigorate process models through the development of eight different embellishment components to enhance process comprehension.
\end{abstract}

Keywords: Business process models, process model comprehension, process model visualization, process model animation

\section{Introduction}

Business processes are among the most critical organizational assets and their optimization is perceived as the key to cost efficiency and competitiveness [1]. Business processes modeling is used for various practices, such as process improvement, process reengineering, project management, knowledge management and for the analysis and design of process aware information systems (PAIS) [2]. Business process models, or process models for short, provide a means of communication for various communities. Process models can be utilized only if related stakeholders can comprehend them well [3]. Among business professionals, many process stakeholders with different backgrounds and levels of expertise can be found: business analysts, domain experts, process owners and process actors. It is not easy for stakeholders of different backgrounds to understand static process models, as processes are dynamic in nature and carry various types of information [4].

There are many research studies on analysing and enhancing comprehension of process models [3-5]. However, existing research mainly focuses on visualization techniques for static process representations. The need for $3 \mathrm{D}$ visualization and the animation of process models was already identified $[5,6]$, yet there are few -- albeit promising -- studies. Moreover, we observe an emerging trend in the industry to utilize modern multimedia techniques to visualize operations. Some organisations even started to investigate new ways for visualizing process models [7].

Multimedia techniques are utilized in innovative ways (i.e. animation, game, simulation, virtual environment) to recreate static representations in a dynamic way. 
This happens in various domains, such as biological processes, physical phenomena, science, health, mechanical devices, historical information, where they have shown great potential to improve learning [8]. Similar techniques can be exploited in the process modeling field to enhance human comprehension. We foresee an opportunity to combine existing knowledge of static process model visualization with model animation and other dynamic invigoration techniques from the multimedia domain to enhance model comprehension. In our preparatory studies, we identified eight different embellishment components that can add value to invigorate process models. Each component represents a different aspect of a process model that can be invigorated by multimedia techniques. Through usage of these embellishment components in an integrated way, models can be dynamically invigorated and presented to business professionals in a more comprehensible manner. In this paper, we unfold our research plan on invigorating process models so that we can inspire other researchers and motivate them to team up with us to pursue this line of research.

Research related to existing work on enhancing process model comprehension and multimedia usage for process modeling is provided in the following section. In Sect. 3 , the embellishment components for which invigoration techniques can be developed are described. Conclusion and the research agenda is described in the final section.

\section{Related Work}

A process model is considered as comprehended if: (1) a mental model of the presented information built by the reader accurately corresponds to what is meant by the modeler, (2) the reader is able to transfer the related information to other tasks, and (3) the mental model is created in the least amount of time possible. Visualization and animation techniques for models can enhance all three aspects.

The basic building blocks of any process model are its nodes and edges. Visualization techniques on static process models change how nodes and edges are displayed. These can be grouped into two categories of techniques that affect the layout and dimensions of a process model (2D vs. 3D): The layout of a process model affects either (1) concrete syntax [9]; i.e. symbols, colours and position of nodes; or (2) abstract syntax [10]; i.e. process elements and their structural relations. Some visualization techniques that affect the abstract syntax are block structuring, duplication, compacting, modularization, and others that affect the concrete syntax are layout guidance, highlighting, annotation. In studies, syntax highlighting for block structures proved to enhance comprehension [11] and a third dimension allowed for more information to be integrated in an understandable way $[12,13]$.

There is limited research on dynamic process representation. Mainly two animation techniques are used; continuous movement by letting tokens flow from one node to another [14] and highlighting of the objects [15]. These studies provide a qualitative judgement that the techniques indeed enhance understanding. The design of animation scenario is another topic of study. In the existing studies, the sequence of steps to be animated was defined in either a script by means of a graphical interface [14], or defined by the analysts $[16,17]$. Design of animation sequence can be based on event $\operatorname{logs}$, too, either using simulation data or by observed behavior $[14,15]$. 
Cognitive theory of multimedia learning and its principles provide valuable insights on how to animate process models to enhance their comprehension [8]. The theory guides us on how to utilize human working memory to present information, engage readers in cognitive process and use multiple sensory pathways. We found studies indicating benefits as well as inconclusive results on using animation for multimedia learning. One study shows that when animation effects are used, such as highlighting or cueing, listeners do direct their attention better $[18,19]$. In other studies, different conclusions are reached for the effect of three cueing types on a process retention and transfer task and perceived ease of use [19, 20]. A meta-analysis reports on the overall advantage of instructional animations over static pictures for acquiring knowledge [14]. Yet another study reports that a combination of animation and narration yields better results [21]. User controls (such as rewind, pause, play, jump, rotating and scaling of 3D models) and pacing style of the animation also affect comprehension [18]. Personal factors is a final dimension worth mentioning that affects understanding of process models [3].

In summary, there has been a lengthy debate on benefits of learning from animations or dynamic representations [22]. In contrast to studies in multimedia learning, the results for using animation in process models are restricted in terms of coverage for different techniques and their effect on enhancing comprehension. Further research is required to examine which techniques regarding process model invigoration could enhance process model comprehension.

Dynamic visualization of process models by means of diverse embellishment components may affect comprehension positively in various ways. When the user reads a static diagram, she has to create a mental model of the overall diagram and alternative sequence of steps. When animation is used, the construction of this mental model is supported. Multiple process executions can be visualized by using one dynamic model, since animation effects can appear and disappear. Combining process model animation with narration may result in even more effective learning due to simultaneous usage of both sensory pathways.

To our knowledge, there exists no research up to date which evaluated the effects of animations using a popular process modeling notation or methods or guidelines on how to define animated scenarios. Most important of all, there are limited amount of techniques used for each component we identified for invigorating process models, and the results for evaluation of these techniques are very scarce.

\section{Embellishment Components}

We aim to combine existing knowledge of static process model visualization with knowledge of model related animation techniques and dynamic media in multimedia learning and reveal possible innovative ways of dynamic media applications on process models. For this, we plan to develop invigoration techniques for control-flow oriented modeling notations. We identified 8 potential embellishment components that can be used in an integrated way to invigorate process models.

Component 1-Animation and visualization techniques for 2D and 3D models: Animation and visualization techniques that can be used to enhance process model 
comprehension will be examined in detail. Although there are existing techniques such as continuous movement, highlighting and cueing; there is still room to develop other techniques and use them in an integrated way to cover different needs of process models for diverse purposes. Principles from multimedia and learning fields, such as cognitive theory of multimedia learning, will be utilized to develop the techniques. We aim to develop and compare animations for $2 \mathrm{D}$ and $3 \mathrm{D}$ visualization. In collaboration with the studies of Component 6 , visualization of additional information added to third dimension will be identified.

Component 2-Identification/design of animation scenario: For any animation technique used, an animation scenario also needs to be defined to determine how the animation runs. Multiple methods for scenario definition may not be sufficient under different conditions. When event logs are available, the scenario can be defined automatically by using historical information. If data is not available, it may be designed by an analyst or identified by the user during animation. This component includes the design of different animation scenario identification techniques.

Component 3- Animations for process model layout: Visualization techniques will be developed for process model layout. Example patterns for which visualization techniques will be developed are; for concrete syntax, highlighting and annotations; for abstract syntax, block structuring and modularization.

Component 4-User controls: Possible user controls during an animation affect how the user interacts with the model. Depending on the aim, lack of user control or rather various user control options and pacing may be helpful to enhance understanding. User controls specific to the visualization techniques developed will be designed.

Component 5- Usage of narration and on-screen text: This component includes the integration of narration and on-screen text with animation and visualization techniques. However, narration may not be applicable at all times and will be substituted with on-screen text.

Component 6-Embedding process perspectives: This component is highly correlated with Component 1. Integration of data, organisation and other perspectives (such as time, performance) for different animation techniques will be investigated. Other possible perspectives that can add value to the models (such as time, performance) and their visualization will also be examined.

Component 7-Mode of operation: A majority of people using process models consist of PAIS users. They often complain that they get lost as to the big picture and state that they feel the need to understand the overall system in greater detail. When the users consult to process models to develop an understanding of the system, a link between the PAIS can provide information on where the user is in the process models. This component includes the design of modes of operation (offline and in interaction with PAIS) to provide context-awareness to a user while she uses a PAIS.

Component 8-Tailoring for personal factors: No matter how "good" we design our visualization methods, it may not be as efficient for users of different types and with various levels of expertise. This component includes an investigation of how personal factors affect the comprehension and tailor the techniques defined in other components for personal factors. Specifically, the needs of different target groups will be examined: business analysts and process owners.

When the techniques developed for all these components are aggregated, they are expected to constitute various ways to invigorate the process models. These can be 
utilized by users for different conditions and purposes. An important contribution of this line of research will be the evaluation of the effect of different invigoration techniques on process model comprehension. There are a few studies proposing dynamic visualization techniques on process models, yet systematic evaluations for impact of these techniques on understanding are even more limited. Experiments to understand the effect of different invigoration techniques on comprehension of process models using evaluation techniques from multimedia learning and instruction are valuable. Methods such as eye tracking, retention, and transfer tasks will be used.

\section{Conclusion and Future Work}

In the presented line of research, we aim to investigate and develop techniques to enhance the comprehension of process models by embellishing them in various ways, combining process modeling and multimedia techniques, thus invigorating what are up till now static process models. In our preparatory studies, we identified eight different embellishment components. We explained potential techniques to be developed for these components to invigorate processes from different aspects.

Our findings from the previous section reveal that systematic evaluations for impact of process model visualization techniques on comprehension are limited. An important contribution of this research will be the evaluation of the effect of different invigoration techniques on process model comprehension. Experiments will be designed using methods from multimedia learning and instruction, such as eye tracking, conduct of retention and transfer tasks. Lastly, to enable widespread application of the invigoration techniques in real life settings, an open source tool will be developed as part of mainstream process modeling platforms.

We hope that this paper inspires other investigators to develop innovative ways to improve the understanding of process models and welcome proposals for collaboration.

Acknowledgments. This project has received funding from the European Union's Horizon 2020 research and innovation programme under the Marie Sklodowska-Curie grant agreement No 660646. We thank Romain Emens for his review of the literature that has been incorporated in this study.

\section{References}

1. Bobs Guide: BPM more important to UK businesses than the rest of Europe, http://www.bobsguide.com/guide/news/2006/Oct/17/bpm-more-important-to-ukbusinesses-than-the-rest-of-europe-but-lags-behind-on-delivery-filenet-surveyreveals.html.

2. Becker, J., Rosemann, M., Uthmann, C. Von: Guidelines of Business Process Modeling. Business Process Management (2000). pp. 30-49. Springer (2000).

3. Reijers, H. a., Mendling, J.: A Study Into the Factors That Influence the Understandability of Business Process Models. IEEE Trans. Syst. Man, Cybern. Part A Syst. Humans. 41, 449-462 (2011). 
4. Recker, J., Reijers, H.A., Wouw, S.G. van de: Process Model Comprehension: The Effects of Cognitive Abilities, Learning Style , and Strategy. Commun. Assoc. Inf. Syst. Vol. 34, 199-222 (2014).

5. Mendling, J., Strembeck, M., Recker, J.: Factors of process model comprehension-Findings from a series of experiments. Decis. Support Syst. 53, 195-206 (2012).

6. Rosemann, M.: Potential pitfalls of process modeling: part A. Bus. Process Manag. J. 12, 249-254 (2006).

7. Shell: Strategic Report - Business overview, http://reports.shell.com/annualreport/2013/strategic-report/our-businesses.php.

8. Mayer, R.E., Moreno, R.: Animation as an Aid to Multimedia Learning. Educ. Psychol. Rev. 14, 87-99 (2002).

9. Rosa, M. La, Hofstede, A.H.M. Ter, Wohed, P., Reijers, H.A., Mendling, J., van der Aalst, W.M.P.: Managing Process Model Complexity via Concrete Syntax Modifications. IEEE Trans. Ind. Informatics. 7, 255-265 (2011).

10. La Rosa, M., Wohed, P., Mendling, J., ter Hofstede, A.H.M., Reijers, H. a., van der Aalst, W.M.P.: Managing Process Model Complexity Via Abstract Syntax Modifications. IEEE Trans. Ind. Informatics. 7, 614-629 (2011).

11. Reijers, H. a., Freytag, T., Mendling, J., Eckleder, A.: Syntax highlighting in business process models. Decis. Support Syst. 51, 339-349 (2011).

12. Betz, S., Eichhorn, D., Hickl, S., Klink, S., Koschmider, A., Li, Y., Oberweis, A., Trunko, R.: 3D Representation of Business Process Models. MobIS 2008. pp. 79-93 (2008).

13. Schönhage, B., Ballegooij, A. van, Eliens, A.: 3D Gadgets for Business Process Visualization - a case study —. Proceedings of the fifth symposium on Virtual reality modeling language (Web3D-VRML). pp. 131-138 (2000).

14. Philippi, S., Hill, H.J.: Communication support for systems engineering - process modelling and animation with APRIL. J. Syst. Softw. 80, 1305-1316 (2007).

15. Günther, C.W.: Process Mining in Flexible Environments, (2009).

16. Nawrocki, J., Nedza, T., Ochodek, M., Olek, L.: Describing Business Processes with Use Cases. Business Information Systems - BIS 2006. pp. 13-27 (2006).

17. Gemino, A.: Empirical comparisons of animation and narration in requirements validation. Requir. Eng. 9, 153-168 (2003).

18. Jamet, E., Gavota, M., Quaireau, C.: Attention guiding in multimedia learning. Learn. Instr. 18, 135-145 (2008).

19. Boucheix, J.-M., Lowe, R.K., Putri, D.K., Groff, J.: Cueing animations: Dynamic signaling aids information extraction and comprehension. Learn. Instr. 25, 71-84 (2013).

20. Jamet, E.: An eye-tracking study of cueing effects in multimedia learning. Comput. Human Behav. 32, 47-53 (2014).

21. Morett, L.M., Clegg, B. a., Blalock, L.D., Mong, H.M.: Applying multimedia learning theory to map learning and driving navigation. Transp. Res. Part F Traffic Psychol. Behav. 12, 40-49 (2009).

22. Höffler, T.N., Leutner, D.: Instructional animation versus static pictures: A metaanalysis. Learn. Instr. 17, 722-738 (2007). 